\title{
EDITORIAL
}

\section{In This Issue: Race, Place, and Sex Matter}

\author{
Jobn J. Frey III, MD \\ Ann Fam Med 2010;8:2-3. doi:10.1370/afm.1031.
}

$\mathrm{T}$ hree articles in this issue focus on how and where social determinants of health intersect with personal genetic factors in communities to create higher and lower risk groups for cardiovascular disease. Fiscella and Franks add to the increasing evidence that a low level of vitamin $\mathrm{D}$ is an independent risk factor for cardiovascular disease, and they show that older African Americans are particularly at increased risk for both heart disease and vitamin D deficiency. ${ }^{1}$ Population-based clinical trials of sufficient magnitude should determine whether supplementation might reverse the effect and could add an important prevention component that would have a large effect on cardiovascular health disparities.

Rural populations in the world suffer from problems of access to care, education, and income disparities, and Sun and colleagues find a dramatic increase in hypertension as an additional risk factor in rural life in China. ${ }^{2}$ Supported by studies in other countries which show less-dramatic but equally important increases in rural populations, the authors speculate that the almost $25 \%$ incidence of new hypertension over a 5 -year period in a large population sample from a single rural province may represent the internalized stresses of adapting to a rapidly changing economic and cultural landscape in China.

Tabenkin and colleagues look at the role that sex of the physician plays both in behaviors by physicians and in recommendations to patients. ${ }^{3}$ Chart audits of patients from randomized practices found that women physicians attend to patients' preventive health issues more consistently than men do. That is the good news. The bad news is that women patients, regardless of physician sex, were less actively treated for cardiovascular prevention in diabetes. As the proportion of women physicians in primary care grows worldwide, including physician sex as a variable in health services and clinical care research seems essential.

A preventive strategy runs into problems of media and culture in Wood and colleagues' description of interview data about food choice with mothers from a wide range of social class backgrounds in a Welsh working class community. ${ }^{4}$ What mothers know and what they do is quite different, a finding that speaks to the need to imbed prevention interventions in the cultural and community context of our work. ${ }^{5}$

The 1966 Folsom Report on community health was titled Health is a Community Affair. ${ }^{6}$ This report recommended that, for tangible improvements in health, clinicians partner creatively with social services, government, education, food systems, and community groups of all types. Kaufman and colleagues ${ }^{7}$ describe a rural New Mexico experience modeled after the Cooperative Extension System services associated with all US Department of Agriculture Land-Grant schools, which offers an updated framework for the Folsom Report. Their exciting model of place-based collaborative work, using a combination of university-connected agents, or faculty, living in communities and working to create connections between health systems and the broad range of social networks, could be reproduced in all cities and towns, not just the rural focus they chose in New Mexico.

One article touches on the internal workings of practice. Bastholm Rahmner and colleagues point to the distressing diversity of opinion about a responsibility for general practitioners to help their patients understand how to use their medications safely. ${ }^{8} \mathrm{~A}$ recent experience with my mother-in-law's primary doctor's answer to her request to review her complex medication list - where the physician said bluntly, "I don't have time to do this" - indicates that this problem is not confined to Sweden. If family doctors do not take responsibility for this issue, then they should bear the litigious consequences for the safety and cost issues that result.

Vannoy and colleagues conducted a subanalysis of a study on depression to find out whether primary care clinicians, to help sort out a higher-risk group of depressed patients, are inquiring about suicide in both sensitive and direct ways. ${ }^{9}$ It seems, for the most part, they are.

I was taught many years ago to consider unexplained lower extremity thrombophlebitis as an alert to look for concomitant cancer. Van Doormaal and colleagues, in a well-designed study in primary care, found that, for a single episode of superficial thrombo- 
phlebitis at least, there is no increased risk of cancer when compared with a control group. ${ }^{10}$

Finally, 2 high-quality systematic reviews illuminate clear evidence-based approaches to using steroids in acute pharyngitis (it does not help) ${ }^{11}$ and whether circumcision is safe in higher risk populations (it is). ${ }^{12}$

Please join the discussion of these articles at http:// www.annfammed.org.

To read or post commentaries in response to this article, see it online at http://www.annfammed.org/cgi/content/full/8/1/2.

\section{References}

1. Fiscella $K$, Franks $P$, Vitamin $D$, race, and cardiovascular mortality: findings from a national US sample. Ann Fam Med. 2010;8(1):11-18.

2. Sun Z, Zheng L, Detrano R, et al. Incidence and predictors of hypertension among rural Chinese adults: results from Liaoning province. Ann Fam Med. 2010;8(1):19-24.

3. Tabenkin H, Eaton CB, Roberts MB, Parker DR, McMurray JH, Borkan J. Differences in cardiovascular disease risk factor management in primary care by sex of physician and patient. Ann Fam Med. 2010;8(1):25-32.

4. Wood F, Robling M, Prout H, Kinnersley P, Houston H, Butler C. A question of balance: a qualitative study of mothers' interpretations of dietary recommendations. Ann Fam Med. 2010;8(1):51-57.
5. Candib LM. Obesity and diabetes in vulnerable populations: reflection on proximal and distal causes. Ann Fam Med. 2007;5(6):547-556.

6. The National Commission on Community Health Services. Health is a Community Affair. Folsom MB, Chairman. Cambridge, MA. Harvard University Press; 1966.

7. Kaufman A, Powell W, Alfero C, et al. Health extension in New Mexico: an academic health center and the social determinants of disease. Ann Fam Med. 2010;8(1):73-81.

8. Bastholm Rahmner P, Gustafsson LL, Holmström I, Rosenqvist $U_{\text {, }}$ Tomson G. Whose job is it anyway? Swedish general practitioners' perception of their responsibility for the patient's drug list. Ann Fam Med. 2010;8(1):40-46.

9. Vannoy SD, Fancher T, Meltvedt C, Unützer J, Duberstein P, Kravitz RL. Suicide inquiry in primary care: creating context, inquiring, and following up. Ann Fam Med. 2010;8(1):33-39.

10. van Doormaal FF, Atalay S, Brouwer H, van der Velde E, Büller $H$, van Weert HC. Idiopathic superficial thrombophlebitis and the incidence of cancer in primary care patients. Ann Fam Med. 2010;8(1):47-50.

11. Korb K, Scherer M, Chenot JF. Steroids as adjuvant therapy for acute pharyngitis in ambulatory patients: a systematic review. Ann Fam Med. 2010;8(1):58-63.

12. Perera CL, Bridgewater FHG, Thavaneswaran P, Maddern GJ. Safety and efficacy of nontherapeutic male circumcision: a systematic review. Ann Fam Med. 2010;8(1):64-72. 